\title{
INTERNACIONALIZAÇÃO DAS UNIVERSIDADES BRASILEIRAS - CONTRIBUI- ÇÕES DO PROGRAMA CIÊNCIA SEM FRONTEIRAS
}

\author{
THE INTERNATIONALISATION OF BRAZILIAN UNIVERSITIES: CONTRIBUTIONS \\ OF THE 'SCIENCE WITHOUT BORDERS' PROGRAMME
}

\author{
Recebido em: 27/11/2018 • Aprovado em: 22/03/2019 \\ Avaliado pelo sistema double blind review \\ Editor Científico: Edson Sadao Iizuka \\ DOI 10.13058/raep.2019.v20n2.1330
}

\section{IVORPROLO ivorprolo@unemat.br}

Universidade do Estado de Mato Grosso

ROSILENE CARLA VIEIRA

MANOLITA CORREIALIMA

Escola Superior de Propaganda e Marketing

FERNANDA GEREMIAS LEAL

Universidade do Estado de Santa Catarina

\begin{abstract}
RESUMO
A crítica ao Ciência sem Fronteiras (CsF) - a maior estratégia governamental de internacionalização na história do ensino superior brasileiro - resultou no interesse em pesquisar as realizações desse programa. Este artigo aborda as contribuições que o CsF tem feito para solidificar a internacionalização nas universidades brasileiras. Para isso, analisa a lógica subjacente à concepção e implementação do programa, seus resultados e, particularmente, sua expansão no nível institucional. A investigação assumiu caráter qualitativo, de natureza exploratória, combinando recursos bibliográficos e documentais por meio da análise temática de conteúdo. Os resultados revelam que o CsF potencializou a exposição das universidades brasileiras no ambiente internacional; favoreceu a criação de parcerias e redes acadêmicas internacionais; influenciou na definição do modelo de internacionalização do Ensino Superior desejado pelo Governo brasileiro. Na medida em que contribuiu para uma curva de aprendizagem e influiu sobre a decisão de se avançar em um processo de internacionalização mais amplo e orgânico, ampliou as condições que criam um ambiente internacional no interior das universidades brasileiras.

Palavras-Chave: Inserção Internacional, Educação Superior, Internacionalização das Universidades, Programa Ciência sem Fronteiras (CsF), Programa Institucional de Internacionalização (PrInt).
\end{abstract}

\footnotetext{
ABSTRACT

Criticism of 'Science without Borders' (SwB) - the largest governmental strategy for internationalisation in the history of Brazilian higher education - has resulted in an interest in investigating the achievements of this programme. This article focuses on the contributions that SwB has made towards solidifying internationalisation in Brazilian universities. To do so, it analyses the rationale underpinning the programme's conception and implementation; its results; and, particularly, its expansion at the institutional level. This qualitative and exploratory research combined bibliographic and documentary resources and used thematic content analysis to do so. Results demonstrate that SwB has enhanced the exposure of Brazilian universities to the international environment, favoured academic partnerships and networks, and influenced the definition of the internationalisation model the Brazilian government wishes to adopt. Since its contribution to the learning curve has induced the decision to move towards a more organic and comprehensive process of internationalisation, it has widened the conditions that create an international environment within universities.

Keywords: International Insertion, Higher Education, Internationalisation of Universities, Science without Borders Programme (SwB), Institutional Internationalisation Program.
} 


\section{INTRODUÇÃO}

Desde a década de 1990 que a globalização econômica influência, em delineamentos mais explícitos e sistemáticos, a definição da política educacional. Em diversos países e regiões se instala uma agenda de reformas inspirada por princípios neoliberais, com a ampliação da participação privada, a redução do investimento público, a adoção de mecanismos de regulação e o reconhecimento da educação superior como um serviço (AKKARI, 2011; CHAVES; CASTRO, 2016; SANTOS, 2011). O Brasil não está alheio a essa agenda; alinha-se ao paradigma científico predominante no século $21 \mathrm{e}$, nesses termos, reconhece a centralidade do desenvolvimento do bem-estar da sociedade pelas lentes da produção resultante do progresso da ciência, da tecnologia e da inovação (VELHO, 2011). Nesse cenário, o conhecimento assume "o status de objeto e produto de políticas governamentais" (FRANÇA; PADILLA, 2015, p. 62). Coerentemente, a pesquisa é concebida como responsável pela geração de conhecimento novo, capaz de promover inovação e influir sobre a competitividade. Apesar das limitações orçamentárias, as nações semiperiféricas investem na formação de jovens com potencial de gerar ciência e tecnologia, criando programas comprometidos com a Mobilidade Acadêmica Internacional (MAI). Por essa via, o governo nutre a expectativa de, em reduzido espaço de tempo, integrar universidades, pesquisadores e estudantes à comunidade científica global (RIVAS; MULLET, 2016, p. 19). Atendo-se ao caso brasileiro, entre 2011 e 2015, o Governo federal implementou o Programa Ciência sem Fronteiras (PCsF) (BRASIL, 2011; MENINO, 2017) com o propósito de criar condições que favorecessem a instalação de processos de modernização, inovação, competitividade e inserção internacional no País (MULLER, 2013), na medida em que fomentava a formação técnico-científica de jovens brasileiros em universidades estrangeiras (ARCHANJO, 2016). Em consonância com tal propósito, criaram-se as condições que permitiram a MAI de expressivo contingente de estudantes -101.446 bolsas foram concedidas no período, das quais $78 \%$ (78.980) destinaram-se à graduação- 
-sanduíche, com um aporte de investimento próximo a $\mathrm{R} \$ 10,5$ bilhões (BUARQUE, 2015; CAPES; CNPQ, 2016).

O levantamento da literatura publicada sobre o PCsF aponta para a existência de lacunas, uma delas é a incipiência de textos cujo conteúdo discute a contribuição do programa para o fortalecimento do processo de internacionalização das universidades brasileiras. Os temas recorrentemente tratados aprofundam aspectos relacionados aos estudantes bolsistas, tais como acesso a MAI (AVEIRO, 2014; KNOBEL, 2012); experiências e efeitos imediatos da MAI sobre os bolsistas (CHAVES, 2015; GIGLIO, 2015; MILHOMEM, 2016; RAMOS, 2016); desafios e conquistas do capital linguístico (ARCHANJO, 2016; BORGES; GARCIA-FILICE, 2016; SEHNEM, 2015), entre outros. Em menor escala, relacionam o PCsF ao Estado nacional desenvolvimentista, à política externa brasileira (BISCHOFF, 2017; JUDD, 2014) e aos reflexos exercidos sobre campos do conhecimento e instituições de ensino superior brasileiras (ALMEIDA, 2016; BASTOS, 2017; COSTA, 2016; LAGE, 2015; RIBEIRO, 2014).

Apesar da visibilidade nacional, sobretudo internacional, alcançada pelo PCsF em virtude do número de bolsistas, volume de recursos financeiros, quantidade de universidades e países envolvidos, além da promessa de colaborar para a inserção do Brasil no cenário internacional, ele foi alvo de inúmeras críticas, tanto por parte de representantes da academia e da mídia impressa e digital, quanto do próprio Governo na gestão posterior à que institucionalizou o Programa. Frente ao exposto, é oportuno questionar de que modo o PCsF contribuiu para o fortalecimento, sobretudo para o direcionamento da política de internacionalização das universidades brasileiras. Para tanto, cabe situar a estratégia governamental que sustentou a concepção e a implantação do Programa, além de significar os seus resultados e desdobramentos para o nível institucional das universidades, no curso dos seus cinco anos (2011-2015) de vigência.

A presente investigação assume um caráter exploratório de natureza qualitativo-interpretativa e baseia-se fundamentalmente em recursos bibliográficos e documentais. Ao reunir artigos acadêmicos, trabalhos stricto sensu e documentos oriundos de múltiplas fontes, tais como agências go- 
vernamentais e não-governamentais, consulados, embaixadas, universidades brasileiras e internacionais, faz uso da técnica de análise temática de conteúdo. As lentes teóricas derivam de um balanço da literatura científica sobre o fenômeno da internacionalização da educação superior. O texto evolui da introdução para os fundamentos teóricos e contextuais que sustentaram o desenvolvimento da pesquisa. Na sequência, o percurso metodológico adotado é descrito. Segue-se a discussão dos resultados, finaliza com as considerações finais e as referências exploradas. 


\section{INTERNACIONALIZAÇÃO DA EDUCAÇÃO SUPERIOR EM PERSPEC- TIVA DINÂMICA: DA MOBILIDADE ACADÊMICA INTERNACIONAL À CONCEPÇÃO ABRANGENTE DO FENÔMENO}

Desde os anos 1990, com a culminação de uma nova era globalizante - que contemplou tanto o aumento da importância conferida ao conhecimento no desenvolvimento das economias quanto a expansão da competitividade em âmbito mundial (JÖNS; HOYLER, 2013) - que a ideia de internacionalização tem despertado especial atenção das instituições universitárias, dos governos nacionais, das agências multilaterais e dos organismos internacionais envolvidos com a educação superior (DE WIT, 1998; DE WIT et al., 2017; EGRON-POLAK; HUDSON, 2014; GAO, 2015; KNIGHT, 2012; LIMA; CONTEL, 2011; MOROSINI; NASCIMENTO, 2017). Para além dos discursos, das políticas e das práticas voltadas ao seu fomento, a internacionalização da educação superior tem se consolidado como recorrente objeto de investigação científica (BERRY; TAYLOR, 2014; DOLBY; RAHMAN, 2008; KEHM; TEICHLER, 2007; YEMINI; SAGIE, 2015), na expectativa de ampliar a compreensão sobre um fenômeno social complexo, que envolve distintas motivações (ou rationales), estágios, formas de manifestação e consequências (KNIGHT, 2004;2015). Em decorrência dessa complexidade, não há consenso sobre seu significado (DE WIT, 1998; KNIGHT, 2004; WHITSED; GREEN, 2014), tampouco há clareza sobre os caminhos a serem percorridos para que os sistemas educacionais e as instituições universitárias se internacionalizem (KNIGHT, 2015)ํ. Knight (2012) aponta para alguns dos possíveis entendimentos:

Para alguns, significa uma série de atividades internacionais, como mobilidade acadêmica de estudantes e professores; estabelecimento de re-

1 As lentes epistemológicas adotadas para a abordagem da internacionalização também se distinguem. De modo geral, o campo tem se desenvolvido com fortes pressões políticas (KEHM; TEICHLER, 2007), em grande medida distanciado dos debates sobre os riscos que o excesso de racionalidade econômica tem conferido ao setor educacional e à sociedade (RUBIÃO, 2013). Todavia, é crescente a quantidade de pesquisadores, tanto dos centros do sistema mundial quanto das semiperiferias e periferias, que questionam a ideia de internacionalização como "bem incondicional" (MORLEY et al., 2018) e apontam para as contradições e os dilemas atrelados ao processo, assim como para a sua base colonial (LEAL; MORAES, 2018; STEIN, 2017). 
des, parcerias e projetos internacionais; novos programas acadêmicos e iniciativas de pesquisa internacionais. Para outros, significa oferecer educação a outros países por meio de novos tipos de arranjos, tais como filiais ou franquias, com uso de uma variedade de técnicas nas modalidades presencial e a distância. Para muitos, significa incluir uma dimensão internacional, intercultural ou global no currículo e no processo de ensino-aprendizagem. Outros ainda concebem a internacionalização como meio para melhorar as classificações nacionais ou mundiais de sua instituição nos rankings ou recrutar os melhores e mais brilhantes acadêmicos internacionais (KNIGHT, 2012, p. 22, tradução nossa).

A definição mais difundida para o fenômeno (MARINGE; FOSKETT; WOODFIELD, 2013; WHITSED; GREEN, 2014; YEMINI; SAGIE, 2015) é proposta pela autora (KNIGHT, 2004), que concebe a internacionalização de forma ampla, como o processo de integração das dimensões internacional, intercultural e global aos propósitos, às funções primárias e à entrega da educação superior, com vistas ao alcance ou aprimoramento de objetivos que transitam entre socioculturais, políticos, acadêmicos, econômicos, mercadológicos, entre outros.

Whitsed e Green (2014) colocam em dúvida definições recorrentemente propostas, incluindo a de Knight (2004), por considerarem que nenhuma delas é isenta de desafios teóricos e operacionais ou ideologicamente neutra. Segundo esse entendimento, a internacionalização diz respeito a um construto multifocal com significado contextual específico; refere-se a um conjunto de atividades agrupadas e classificadas por meio de rotulação de suas relativas conotações e de qualidades localizadas entre aqueles que utilizam o termo, cujas expectativas e experiências com tais atividades divergem. Em suas palavras, "dado que as experiências com a internacionalização se alteraram radicalmente ao longo do tempo, e em diferentes lugares, [...], o contexto histórico e sócio-cultural específico do nomeador [do rótulo 'internacionalização'] é significativo; enquadra qualquer ato de avaliação" (WHITSED; GREEN, 2014, p. 112, tradução nossa).

Essa perspectiva enfatiza o caráter circunstancial do fenômeno, sobretudo quando se leva em conta a presença de um ambiente altamente 
institucionalizado e pluralístico, como o da educação superior, no qual se observa uma série de ordens normativas, constituídas por mais de uma lógica cultural, com diferentes prescrições para a ação (MARGINSON; ORDORIKA, 2011). Portanto, ao mesmo tempo em que as instituições universitárias se integram fortemente a um sistema nacional - no qual os governos e as instituições intermediárias moldam as regras e outras formas de controle que afetam seu comportamento e suas escolhas existem processos cognitivos e normativos que ultrapassam as barreiras dos Estados. Em outras palavras, há fatores ambientais, organizacionais e intraorganizacionais que influenciam os rumos da internacionalização da educação superior (SEEBER et al., 2016).

No âmbito intraorganizacional, isso significa que as instituições universitárias dispõem de objetivos próprios relacionados à internacionalização e que eles são influenciados pelos atores internos (SEEBER et al., 2016). Maringe, Foskett e Woodfield (2013) identificam quatro grandes áreas de criação de valor que tais instituições esperam alcançar com a internacionalização: $1^{\circ}$ ) valor estratégico e simbólico; $2^{\circ}$ ) valor de criação de conhecimento (capital social e intelectual); $3^{\circ}$ ) valor de integração cultural; e $4^{\circ}$ ) valor de mercado global. Dobbins (2015), por sua vez, faz uso dos conceitos de morfismo institucional e institucionalismo histórico ao argumentar como as pressões isomórficas externas, oriundas da transnacionalização da educação superior, são canalizadas de diferentes formas pelas instituições universitárias, que têm particularidades decisivas para as reações nacionais. Desenvolvimentos políticos, portanto, estão condicionados a legados e estruturas. Como Araya e Oregioni (2015, p. 7, tradução nossa) argumentam, "a universidade se identifica como agente e ator da internacionalização, possui sua própria lógica e características político-institucionais, que definem em grande medida a forma de gestão desse processo". Sánchez, Muñoz e Benítez (2015), por sua vez, advertem que essa gestão não é um fenômeno neutro, uma vez que contempla dimensões políticas. Em outras palavras, o entendimento acadêmico-científico dos gestores universitários sobre a internacionalização faz com que eles disponham de uma base cognitiva e orientadora sobre o processo. 
$\mathrm{Na}$ prática, os indicadores mais comumente associados à internacionalização do ensino estão associados à MAI e a internacionalização do currículo; à pesquisa expressa em projetos transfronteiriços de investigação e publicações conjuntas (EWERT, 2012), sendo que, de todas as formas de manifestação, a MAI se constitui como a mais recorrente ${ }^{2}$ (KEHM; TEICHLER, 2007) e a mais visível (LIMA; CONTEL, 2011). A ênfase depositada nessa dimensão pode ser observada a partir de diversos indicativos. $\mathrm{Na}$ Europa, por exemplo, a sistematização da MAI por meio do European Region Action Scheme for the Mobility of University Students (Erasmus) serviu como base para estágios mais avançados de alinhamento entre os sistemas de educação superior da região, como o Processo de Bologna, a Estratégia de Lisboa e a European Higher Education Area (EHEA) (AZEVEDO, 2014; SHIELDS, 2014). Além disso, no campo da pesquisa em internacionalização da educação superior, o tema mobilidade estudantil é o mais recorrente nas publicações disponíveis (KEHM; TEICHLER, 2007; YEMINI; SAGIE, 2015), inclusive em teses e dissertações brasileiras (MOROSINI; NASCIMENTO, 2017). Finalmente, os resultados do 4th Global Survey on Internationalization da International Association of Universities (IAU) ${ }^{3}$ reconhecem que as atividades de internacionalização priorizadas pelas instituições universitárias são a MAI e a colaboração internacional voltada para a pesquisa (EGRON-POLAK; HUDSON, 2014).

Mais recentemente, a internacionalização tem adquirido contornos mais estruturais, inclusive em termos conceituais, pois no lugar de ser indiscriminadamente associada a uma ou mais de suas dimensões - a exemplo da MAI ou da internacionalização do currículo - passa a representar mudanças transversais (GACEL-ÁVILA; RODRÍGUEZ-RODRÍGUEZ, 2018). A difusão do conceito de "internacionalização abrangente" (comprehensive

2 Segundo o relatório Education at Glance 2016 da Organização para a Cooperação e Desenvolvimento Econômico (OCDE), o número de estudantes matriculados em universidades de outros países cresceu mais de 50\% no período de 2005 a 2012 (OECD, 2016). A versão de 2017 desse relatório relata que o número de estudantes estrangeiros em cursos superiores cresceu de 0,8 milhão no final dos anos 1970 para 4,6 milhões após 45 anos. Em 2015, havia 3,3 milhões de estudantes viajando nos países da OCDE para fins de estudo (OECD, 2017).

3 Aplicado em 1.336 instituições universitárias de 131 países de todas as regiões do mundo, sendo a maioria delas pública, focada em ensino e pesquisa, com oferta de cursos em todos os níveis e relativamente pequena em termos de números de matrículas (EGRON-POLAK; HUDSON, 2014). 
internationalization), cada vez mais presente nos discursos e na agenda de pesquisa sobre o tema, reflete essa tendência. Para Hudzik (2011, p. 6, tradução nossa), a internacionalização abrangente diz respeito a:

Um comprometimento, confirmado por meio da ação, de infundir perspectivas internacionais e comparativas ao longo das missões de ensino, pesquisa e serviços da educação superior. A internacionalização abrangente molda o ethos e os valores institucionais e envolve todo o empreendimento universitário. É essencial que ela seja abraçada pela liderança e pela governança institucional, pelos professores, pelos estudantes e por todas as unidades de serviço e de apoio acadêmico. Trata-se de um imperativo institucional, não apenas de uma possibilidade desejável (HUDZIK, 2011, p. 6, tradução nossa).

Em consonância com essa concepção, os investimentos voltados à internacionalização deixam de ter os indivíduos como o principal alvo, a exemplo dos programas governamentais de MAI promovidos no interior de diversos sistemas de educação superior pelo mundo, para focar mais diretamente nas universidades de pesquisa como meio de inserir-se "ativamente" (LIMA; CONTEL, 2011) no contexto da economia do conhecimento. 


\section{O PROGRAMA CIÊNCIAS SEM FRONTEIRAS (PCSF)}

O PCsF, vigente de 2011 a 2016, foi concebido e implantado pelo Governo federal com o propósito principal de promover a internacionalização da educação superior brasileira. Comprometia-se a colaborar com a formação superior de alto nível na medida em que os bolsistas frequentariam cursos e laboratórios de pesquisa nos centros de excelência acadêmica internacionais. Simultaneamente, apoiava a atração de pesquisadores seniores e recém-doutores estrangeiros, interessados em colaborar com a produção e a difusão de conhecimento nas universidades brasileiras. Essas ações convergiam para propósitos mais ambiciosos: contribuir para a ampliação e consolidação de redes internacionais de pesquisa; acelerar o processo de internacionalização das universidades brasileiras (CAPES, 2017), consequentemente elevar a visibilidade internacional das referidas instituições; além de promover a pesquisa científica e técnica capaz de influir sobre a inovação e a competitividade do setor produtivo do País (BRASIL, 2011), em consonância com a perspectiva desenvolvimentista que tem caracterizado as iniciativas de internacionalização da educação superior brasileira (LIMA; CONTEL, 2009).

A ideação do PCsF combina a inspiração gerada pela política de MAI adotada há quase vinte anos pelo governo chinês às provocações do governo estadunidense. Em 2011, por ocasião do IV Diálogo de Parceria Global Brasil-EUA, em meio à crise financeira deflagrada em 2008, o então presidente Barack Obama chama atenção para a expressiva presença de acadêmicos chineses, indianos e sul coreanos nas universidades estadunidenses, comparativamente ao modesto número de brasileiros. Considerando os recursos financeiros que cada acadêmico internacional representa para o país, governo e universidades estadunidenses redobraram esforços para atrair grandes estoques (BIDO, 2015; CASTRO et al., 2012; JUDD, 2014). É nesse contexto que o plano 100,000 Strong in the Americas é elaborado, tendo o presidente Obama como porta-voz. Assim sendo, no curso da referida reunião foram assinados acordos de cooperação internacional entre os dois países e três meses depois (jul./2011) o PCsF é 
inaugurado. Entre entusiasmo e desconfiança, as universidades brasileiras foram informadas de que o programa concederia 101.000 bolsas de estudos (AVEIRO, 2014). Inicialmente, objetivava-se enviar os bolsistas para as universidades estadunidenses, frente à dificuldade de em pouco tempo concretizar esse propósito, o governo brasileiro expandiu as parcerias para 54 países (CHAVES, 2015). O lançamento do PCsF suscitou diversas questões: a urgência em se desenhar um programa de MAI ousado e abrangente, de implantação e acompanhamento complexos; envolvendo expressivo número de bolsas, países e universidades; particularmente oneroso para os cofres públicos. Considerando que o investimento médio por bolsista representava R\$ 103 mil e que entre 2011 e 2015 foram investidos cerca de R\$ 10,5 bilhões (BUARQUE, 2015), é possível afirmar que o PCsF se configurou a mais arrojada iniciativa de fomento da MAI financiada pelo governo brasileiro (AVEIRO, 2014, p. 17). A Figura 1 reúne o número de bolsas concedidas para estudo/pesquisa no exterior, discriminando o que coube ao PCsF e aos demais programas ${ }^{4}$.

Os dados revelam crescente assimetria entre o número de bolsas autorizado no PCsF e nos programas tradicionais; moderado crescimento do número de bolsas concedido pelos programas tradicionais; rapidez do crescimento do número de bolsas concedidas entre 2013 e 2014, respectivamente; além do fato de em 2014 o CsF ser o único programa de Governo a promover MAI nas universidades brasileiras. Sublinha-se que em 2013 foi concedido um número de bolsas oito vezes superior aos programas tradicionais e grande parte delas correspondia a bolsas de graduação-sanduíche. Isso permite assegurar que a singularidade do PCsF está no número de bolsas implementadas na modalidade graduação-sanduíche, elas corresponderam a 78\% (78.980) do total de bolsas conferidas entre 2011 a 2015 (CAPES; CNPQ, 2016). Contrariamente à política de MAI até então vigente no País, o PCsF privilegiou iniciantes (estudantes de graduação) em detrimento de acadêmicos iniciados (pós-graduação stricto sensu e estágio de pós doutoral), como também se observa na Figura 1.

4 Das bolsas tradicionais, $5 \%$ correspondem a graduação-sanduiche, enquanto o CsF, este número chega a $78 \%$ das bolsas concedidas (Bido, 2015). 
Figura 1 Número de Bolsas de Estudo/Pesquisa no Exterior - comparativo entre bolsas tradicionais e do Programa Ciência sem Fronteiras

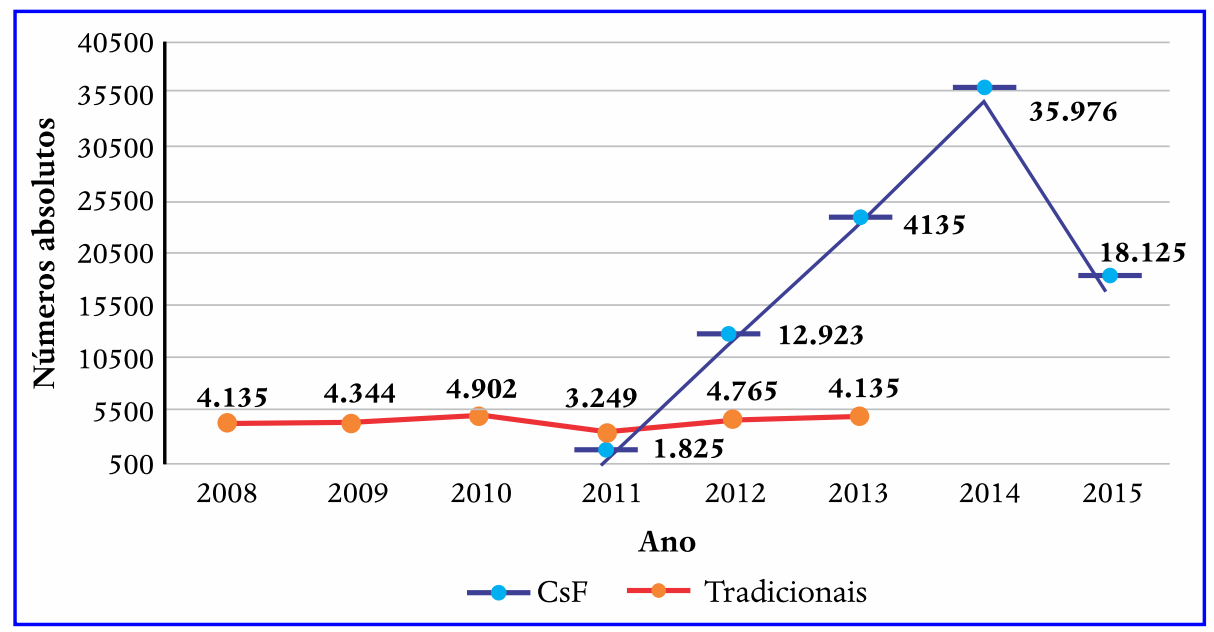

Fonte: CAPES e CNPq (2016); Westphal (2014).

Com as transformações decorrentes da intensificação da globalização, a possibilidade de o setor produtivo das nações semiperiféricas competirem mundialmente depende da existência de quadros cada vez mais qualificados. Nesse contexto, as responsabilidades das universidades se ampliam. Frente ao exposto, qual é a política de internacionalização da universidade adotada pelo governo dos países semiperiféricos? Dados divulgados (Tabela 1) revelam que há expressivo esforço de encurtar o tempo, investindo pesadamente em MAI. Autores como Lima e Contel (2011) e Morosini, Dalla e Guilherme (2017) chamam atenção para a consolidação do processo de internacionalização alcançado pelas universidades dos países centrais, nos quais a internacionalização assume caráter estratégico, ultrapassa os programas de atração de acadêmicos internacionais na direção da promoção de Pesquisa \& Desenvolvimento, em parcerias com empresas internacionais; da geração e registro de patentes, além da comercialização de consultorias a agências governamentais dos países semiperiféricos. No contexto dos países semiperiféricos, até muito recentemente, o fator preponderante do processo de internacionalização das universidades era 
apoiado pela oferta de programas de MAI, a exemplo do que se reúne na Tabela 1. Apesar da centralidade dos referidos programas, em virtude das instabilidades econômicas e das mudanças de governo, recorrentemente sofrem descontinuidades, interrompendo iniciativas em andamento, comprometendo a consolidação do programa e o amadurecimento do processo de internacionalização da universidade, freando relações virtuosas entre universidade e setor produtivo.

Mesmo assim, alguns programas orientados para a promoção da MAI suscitam reflexões críticas por parte de representantes da academia, sendo que as preocupações mais recorrentes questionam o status de "cooperação" (LIMA; CONTEL, 2011); apontam para as relações assimétricas e coloniais entre regiões, países e universidades (LEAL; MORAES, 2018; STEIN, 2017; TERRIER, 2009); chamam atenção para a predominância dos interesses dos países centrais e das organizações internacionais nos rumos do processo (AKKARI, 2011; AZEVEDO, 2014; LEITE; GENRO, 2012; LIMA; CONTEL, 2011); questionam a utilização de indicadores de qualidade que favorecem a cultura acadêmica dos países centrais e negligenciam as especificidades culturais dos demais contextos (VIEIRA; LIMA, 2015); e, frente aos limites orçamentários, questionam o sentido de programas que favorecem poucos em detrimento da expansão e da qualidade do Ensino Fundamental e Médio nos países em desenvolvimento (GACEL-ÁVILA; JOCELYNE, 2012). Isso é particularmente preocupante quando se leva em conta a pressa com que os programas são desenhados, ausência de indicadores de acompanhamento e avaliação dos resultados atrelados à internacionalização. 


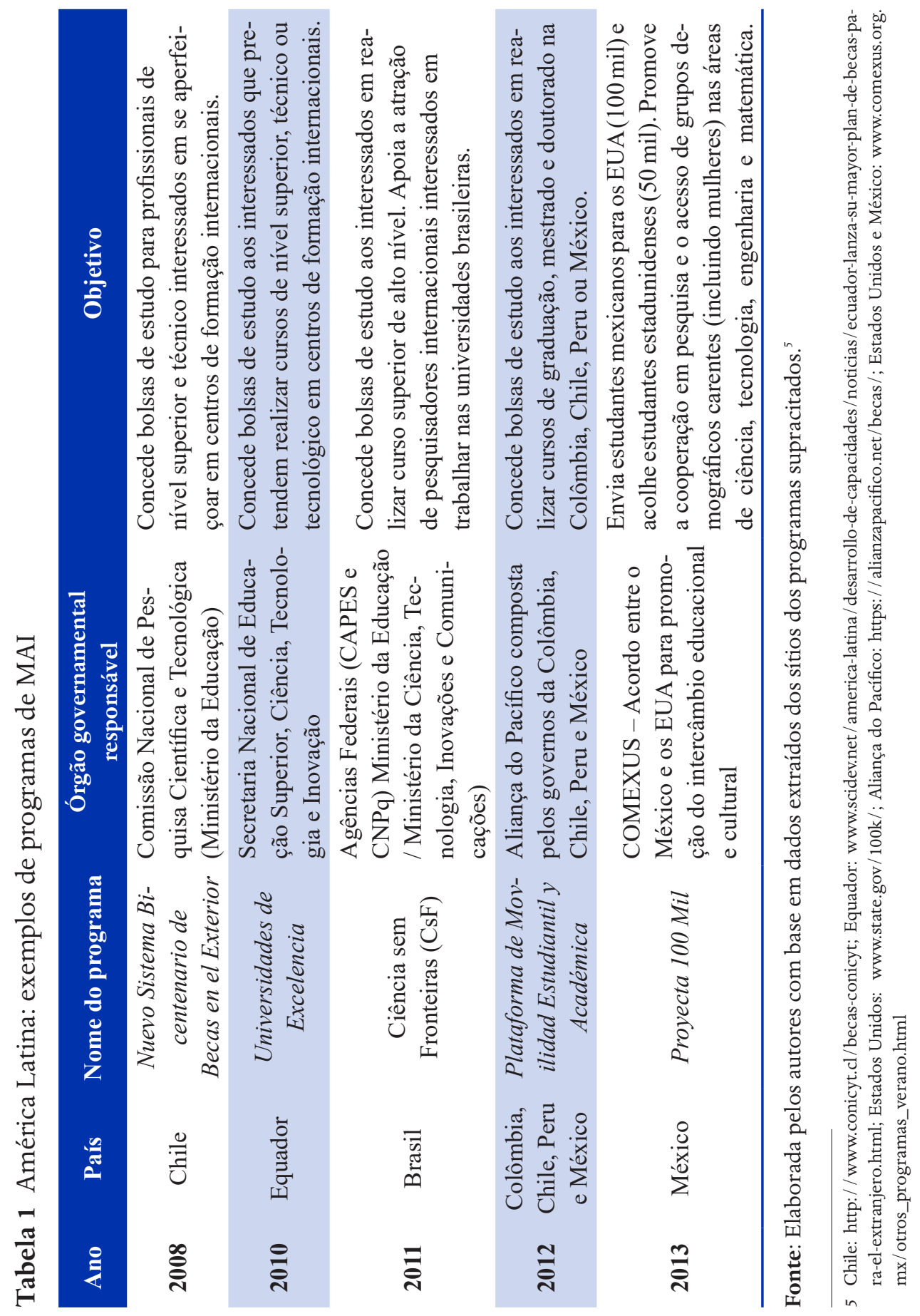




\section{ESCOLHAS METODOLÓGICAS}

Por se tratar de um programa recente, com pouco acompanhamento do processo e dos resultados alcançados, a investigação assume características exploratórias de caráter qualitativo-interpretativas (PRASAD, 2005; STAKE, 2016), combinando recursos típicos das pesquisas bibliográfica e documental. No âmbito da pesquisa bibliográfica foram considerados autores/textos que discutem a internacionalização da educação superior, particularmente a MAI e aspectos relacionados ao PCsF.

Quanto à pesquisa documental, levou-se em consideração documentos de acesso público, oriundos de múltiplas fontes: agências governamentais - Coordenação de Aperfeiçoamento de Pessoal de Nível Superior (CAPES), Conselho Nacional de Desenvolvimento Científico e Tecnológico (CNPq), Senado Federal Brasileiro e Foreign \& Commonwealth Office (FCO) - e não-governamentais - Organisation for Economic Co-operation and Development (OECD), Institute of International Education (IIE), Universities UK, International Unit, US Department of Commerce, Association of International Educators (NAFSA), consulados, embaixadas, universidades brasileiras e internacionais que tiveram expressiva participação no PCsF, relatórios de rankings acadêmicos globais, assim como notícias divulgadas nos principais veículos de comunicação, no Brasil.

O material reunido foi tratado com base na técnica de análise temática de conteúdo, tendo o problema de pesquisa como âncora da interpretação textual (FRANCO, 2007; MORAES, 1999). A leitura do material bibliográfico e documental gerou as categorias de análise (Tabela 2) que orientaram o exercício interpretativo.

Tabela 2 Categorias de Análise

a. PCsF e a exposição das universidades brasileiras no ambiente internacional

b. PCsF e o estabelecimento de parcerias que favorecem os interesses dos EUA e do UK

c. PCsF e o direcionamento institucional da internacionalização nas universidades brasileiras

Fonte: Elaborada pelos autores. 


\section{APRESENTAÇÃO E DISCUSSÃO DOS RESULTADOS}

\section{PCSF e a exposição das universidades brasileiras no ambiente interna- cional}

Dados extraídos da Figura 2 apontam para expressiva concentração no envio de bolsistas para as universidades situadas nos Estados Unidos (27.821) e no Reino Unido (10.740). O fato de grande parte dos países que atraíram os maiores contingentes de bolsistas serem anglofalantes e integrarem o grupo formado pelos países centrais reforça o argumento de que "a internacionalização tem como corolário o aumento do poder da polarização da produção de conhecimento por parte dos países do centro do sistema-mundo" (RODRIGUES; CARRIERI, 2001, p. 93). Contudo, entre os países que acolheram bolsistas do PCsF, encontram-se também a China (na $19^{\circ}$ posição, com 296 bolsistas) - que de acordo com o governo brasileiro, em 2017 foi o maior importador do Brasil -, bem como o Chile (na 24 a posição) e o México (na $27^{\mathrm{a}}$ ), países vizinhos que se destacam no processo de internacionalização na região.

Os países que acolheram os bolsistas do PCsF concentram o maior número de universidades mais bem classificadas nos rankings acadêmicos globais (ARWU, THE e QS). A classificação do THE referente a 2016/2017, por exemplo, revela que entre as cem primeiras universidades classificadas, 41 são norte-americanas (THE, 2017). Apesar de as práticas classificatórias serem objeto de críticas por parte de acadêmicos refratários à instalação de um ambiente marcado pela competição e questionarem a capacidade de mensurarem a qualidade educacional (ALTBACH; HAZELKORN, 2018; LEAL; STALLIVIERI; MORAES, 2017), as universidades brasileiras, sejam elas públicas ou privadas, empenham-se para conquistar elevada posição nos referidos rankings ${ }^{6}$.

6 Observa-se nos portais das universidades brasileiras mais bem classificadas nos rankings que a cada nova classificação há divulgação e comemoração de resultados. Por exemplo, "Na $118^{a}$ posição, USP é a brasileira mais bem avaliada no QS Ranking. É a melhor posição alcançada pela Universidade desde que o ranking começou a ser publicado" (7 de junho de 2018) (USP, 2018); "UFSC ocupa a posição de 101-150a no ranking 'Golden Age University Ranking”, (8 de junho de 2018) (UFSC, 2018). 
Figura 2-PCsF: Distribuição dos Bolsistas por País de Destino (2011-2015)

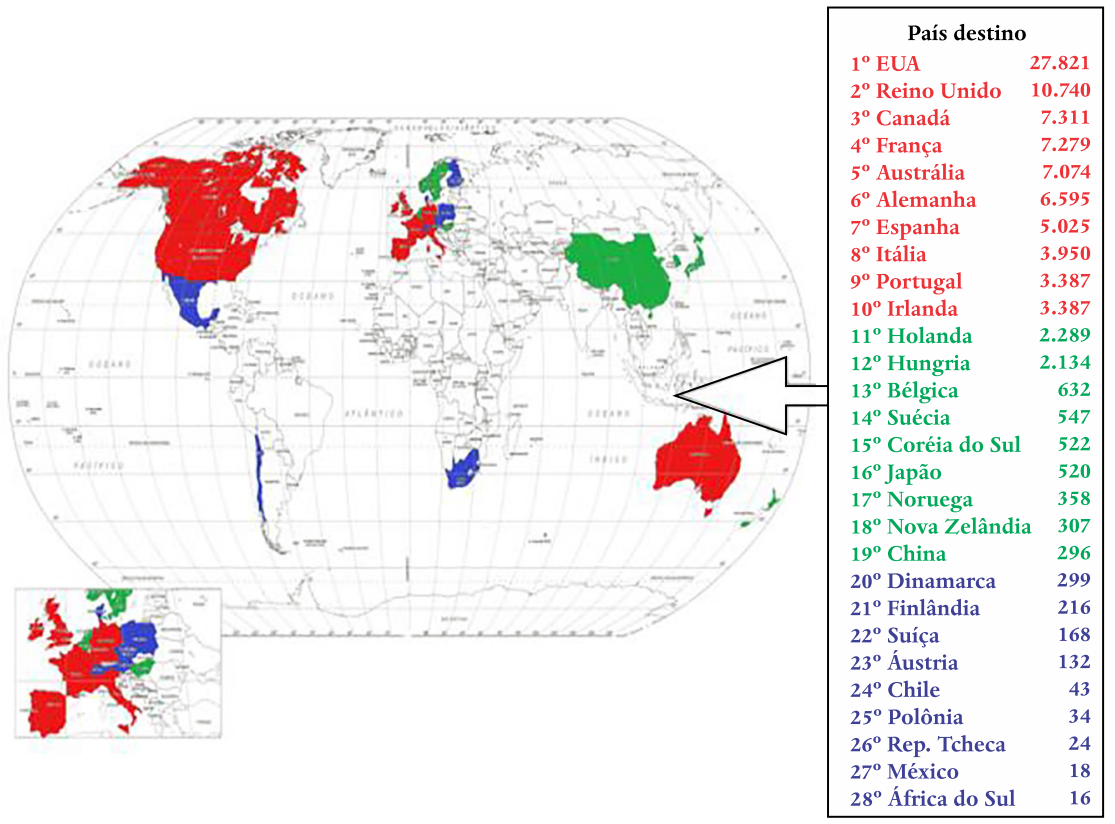

Fonte: CAPES e CNPq (2016).

Além de credibilidade e reputação, boa classificação em tais rankings confere visibilidade internacional, promove a atração de cérebros (pesquisadores, professores, estudantes), matrículas nacionais e internacionais, investimentos público e privado (nacional e internacional) capazes de financiar parte da pesquisa, fatores que reforçam a qualidade e a competitividade das universidades globais e promovem uma espécie de ciclo virtuoso. Segundo a literatura institucionalista (NORTH, 1990; SCOTT, 1995; 2008), para instauração da competição é necessário que se imprimam padrões de concorrência produzidos por meio da interação entre as partes concorrentes, tais como preço, qualidade e diferenciação do produto, a sofisticação das instalações etc. No geral, esses fatores engendram "forças concorrenciais (que) refletem as características estruturais do mercado e as condutas das organizações que nele atuam” (MACHADO-DA-SILVA; FONSECA, 1996, p. 101). 
Assim sendo, os rankings acadêmicos globais "são percebidos e utilizados para determinar o status individual, avaliar a qualidade e o desempenho do sistema de ensino superior, além de mensurar a competitividade global" (HAZELKORN, 2011, p. 4). Evidência disso tem sido a presença de algumas universidades brasileiras nos rankings de 2011 em diante. Dados do Time Higher Education / World University Rankings (THE/TR) revelam que em 2010, ano em que houve o lançamento do PCsF, nenhuma universidade brasileira constava entre as 400 melhores do mundo. Em 2011, ano que marca a inauguração do referido programa, duas universidades são incluídas: a USP aparece entre as 200 melhores ( $178^{a}$ posição) e a Unicamp entre a $276^{\mathrm{a}}$ e $300^{\mathrm{a}}$ posição. Um ano depois (2012), tanto a USP, quanto a Unicamp avançaram 20 posições, enquanto a primeira passa da $178^{\mathrm{a}}$ posição para $158^{\mathrm{a}}$, a segunda migra da $276^{\mathrm{a}}-300^{\mathrm{a}}$ para $251^{\mathrm{a}}-276^{\mathrm{a}}$ (THE, 2017).

Considerando os resultados do QS World University Rankings - Top Universities, de origem britânica, a partir de 2011, três universidades brasileiras elevaram as respectivas posições. Entre as 700 consideradas no ranking, edição 2016, a USP atinge a $120^{a}$ posição. Nos cinco anos de vigência do PCsF, ela avançou 133 posições; a Unicamp 191 e a UFRJ 60. Comparando a presença da USP e da Unicamp, observa-se que entre 2010 e 2011, elas avançaram 84 e 57 vezes as respectivas posições. Se o alcance de elevado padrão de qualidade na Educação Superior é um empreendimento exigente em tempo e recursos, os exemplos sinalizam que se trata mais de uma questão de recursos financeiros disponíveis para investir em MAI (QS, 2017).

A combinação entre a intensificação do processo de internacionalização da educação superior entre os países da América Latina (Tabela 1); a crise financeira enfrentada pelos Estados Unidos; e às críticas direcionadas aos critérios de classificação adotados pelos rankings globais são fatores que contribuíram para um ambiente favorável à criação de rankings acadêmicos regionais. O mundo precisava conhecer evidências que reforçassem a relação virtuosa entre a criação de programas de MAI e elevação da qualidade acadêmica das universidades. Assim sendo, em 2011 a QS cria o primeiro ranking das universidades latino-americanas, o QS Latin American University Rankings. 
Desde a origem, aproximadamente metade das vinte primeiras posições é ocupada por universidades brasileiras (Tabela 3). Em 2012, um ano após o lançamento do PCsF, QS atesta a liderança das universidades brasileiras: entre as 250 melhores do continente, 65 eram brasileiras. A grande maioria das instituições mais bem classificadas nos três rankings é de origem pública. Reveladoramente, elas são as principais responsáveis pelo envio de bolsistas do PCsF (USP, UFMG, UFRJ, UnB, UFSC e Unesp) e aquelas que declaram o compromisso de avançar no processo de internacionalização, além da ambição de conquistar o status de universidade classe mundial no texto dos seus respectivos Planos de Desenvolvimento Institucional (PDI) (THIENGO, 2018). Ademais, esses resultados vão ao encontro das grandes áreas de criação de valor institucional (MARINGE; FORKETT; WOODFIELD., 2013).

Os resultados positivos associados ao PCsF não se reduzem à classificação das universidades brasileiras nos rankings regionais e globais. A interpretação da literatura e dos documentos consultados permitem ampliar as referidas conquistas, como se observa na Tabela 4. A magnitude do programa coloca o Brasil, particularmente as universidades brasileiras, em evidência. Indícios disso são o expressivo número de dissertações e teses que discutem a internacionalização da educação superior brasileira e a criação de grupos de pesquisa voltados ao entendimento desse fenômeno; a promoção de fóruns, workshops e palestras nacionais e internacionais cujo objetivo residia em compreender o PCsF, a universidade e o sistema de ensino superior brasileiro; a presença de delegações internacionais no Brasil; a promoção de visitas de gestores universitários brasileiros a universidades estrangeiras e sua presença nas principais feiras mundiais de educação superior internacional; a criação e lançamento do portal de revalidação/ reconhecimento de diplomas estrangeiro (Carolina Bori), bem como o Programa Institucional de Internacionalização (PrInt), que será abordado mais adiante. 
Tabela 3 QS Latin American University Rankings - TopUniversities (20112017): classificação das universidades brasileiras

\section{Universidade}

$\begin{array}{lllllll}2011 & 2012 & 2013 & 2014 & 2015 & 2016 & 2017\end{array}$

Universidade de São

Paulo (USP)

$\begin{array}{lllllll}1 & 1 & 1 & 2 & 1 & 1 & 3\end{array}$

Universidade Estadual de

Campinas (UNICAMP)

$\begin{array}{lllllll}3 & 3 & 3 & 3 & 2 & 2 & 2\end{array}$

Universidade Federal do

Rio de Janeiro (UFRJ)

Universidade Federal de

Minas Gerais (UFMG)

$\begin{array}{lllllll}19 & 8 & 8 & 4 & 5 & 5 & 7\end{array}$

Universidade Estadual

Paulista "Júlio de Mes-

$\begin{array}{lllllll}16 & 17 & 11 & 9 & 8 & 12 & 10\end{array}$

quita Filho" (UNESP)

Universidade Federal do

Rio Grande do Sul

(UFRGS)

$\begin{array}{lllllll}10 & 13 & 10 & 10^{\star} & 11 & 14 & 11\end{array}$

Universidade Federal de

São Paulo (UFSP)

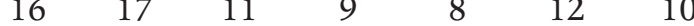

Pontifica Universidade

Católica do Rio de

$\begin{array}{lllllll}15 & 18 & 18 & 13 & 14 & 15 & 13\end{array}$

Janeiro (PUC-RJ)

Universidade de Brasília

(UnB)

$\begin{array}{lllllll}14 & 14 & 14 & 10^{\star} & \begin{array}{l}\mathrm{N} / \\ \mathrm{R} 20\end{array} & 16 & 14\end{array}$

Fonte: QS (2017).

Nota: N/R20: Não Ranqueada entre as 20 melhores. / *: Ranqueadas na mesma posição. 


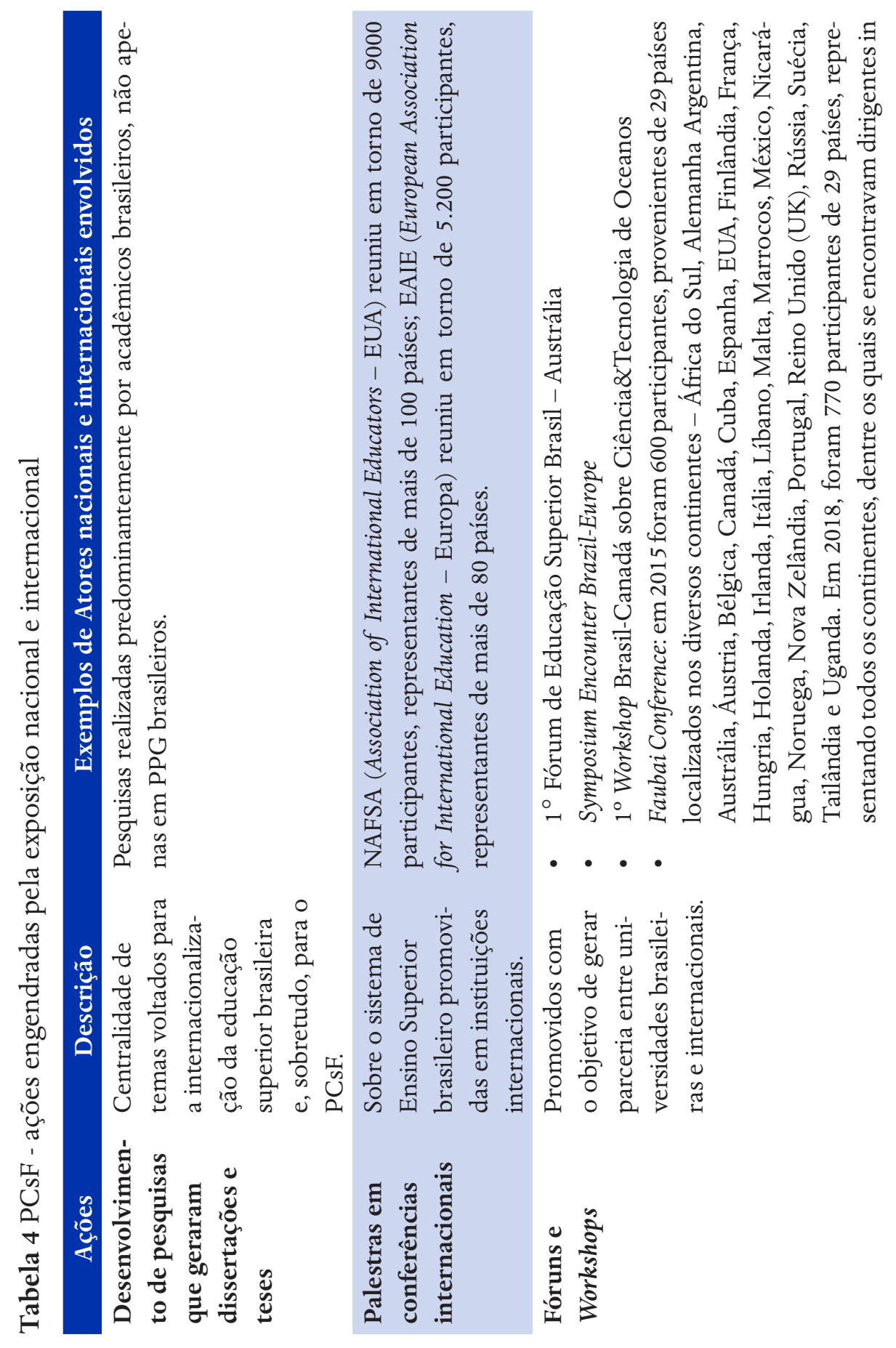




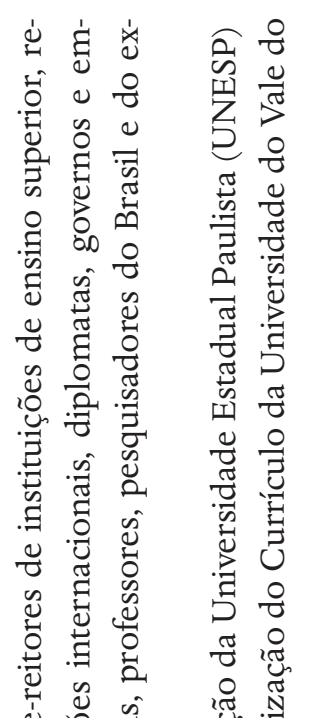

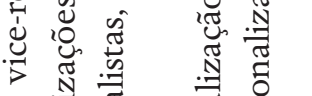

()

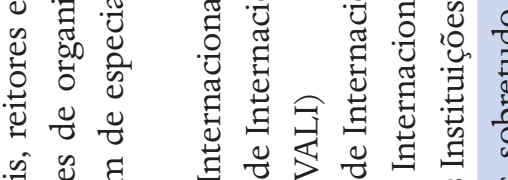

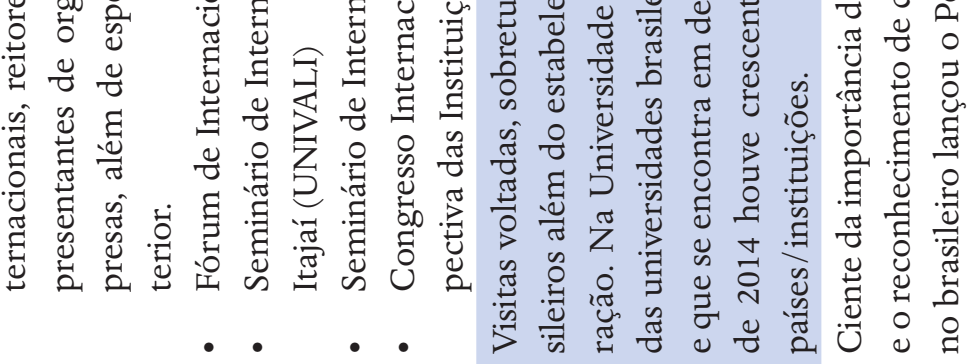

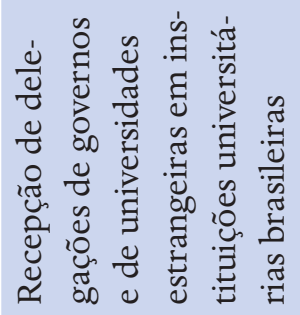

:

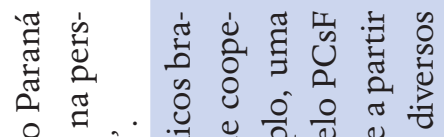

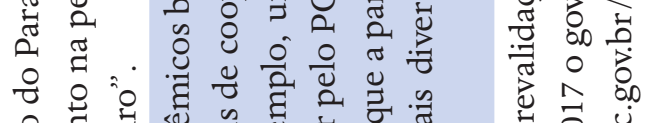

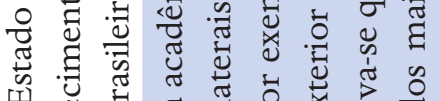

○

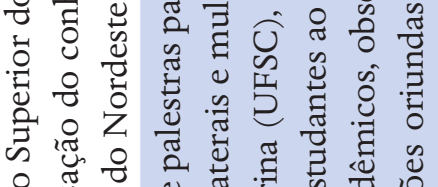

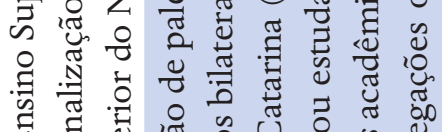

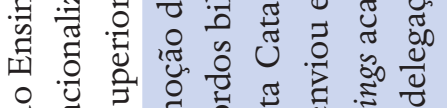

유

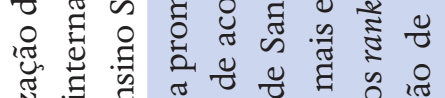

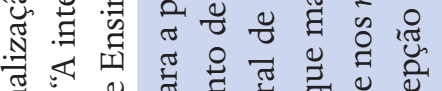

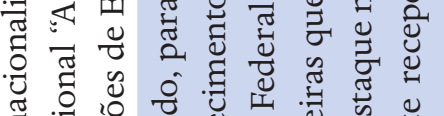

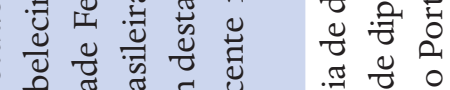

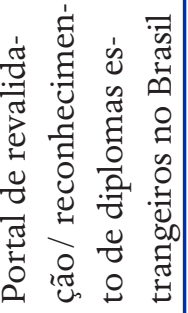

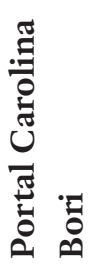

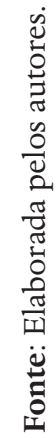


Cada vez mais expostas ao ambiente internacional, algumas universidades brasileiras avançam no diálogo com representantes das agências multilaterais dos países interessados em ampliar o mercado educacional já conquistado e das instituições desejosas de elevar as matrículas internacionais. Para tanto, um grupo de universidades brasileiras investe na definição de projetos de internacionalização, criação ou consolidação de pró-reitorias para assuntos internacionais, contratação de profissionais capazes de trabalhar com uma agenda de internacionalização na expectativa de contar com o apoio das agências de fomento brasileiras (CAPES, 2017).

\section{PCSF e o estabelecimento de parcerias que favorecem os interesses dos EUA e do UK}

Enquanto entre os países semiperiféricos o processo de internacionalização da educação superior transita entre o estágio embrionário e moderado, entre os países centrais, particularmente os Estados Unidos (EUA) e o Reino Unido (UK) o referido processo se encontra consolidado. Não faltam indícios do que foi afirmado: reúnem as universidades mais bem ranqueadas do mundo, atraem os mais expressivos contingentes de acadêmicos, geram patentes, vendem consultorias etc. e com isso podem selecionar e manter os melhores cérebros; dispor de recursos para investir em laboratórios de primeira geração; liderar a geração e difusão de Ciência \& Tecnologia, cientes de que tudo isso favorece a vitalidade do setor produtivo (VIEIRA; LIMA, 2015). O protagonismo dos EUA e do UK na gênese e expansão do PCsF justifica o aprofundamento dos resultados positivos associados a essas duas regiões.

Dada a grandeza acadêmica de algumas universidades estadunidenses, observa-se a atenção conferida aos recursos humanos e à formação de alianças estratégicas. Dados da $\operatorname{OECD}$ (2017, p. 290) revelam que o país atrai aproximadamente um (970.000) dos três milhões de estudantes de nível superior em circulação, trata-se do país que mais acolhe estudantes internacionais. Em termos imediatos, o que isso gera para a economia do país? Dados divulgados pelo Departamento de Comércio Exterior (US Department of Commerce) revelam que em 2015 a educação 
internacional foi responsável pela movimentação de mais de US\$ 35 bilhões na economia norte-americana (OECD, 2017). Dados divulgados pela Association of International Educators (NAFSA, 2018), referentes ao ano acadêmico de 2017-2018, revelam que os 94.562 estudantes internacionais e respectivos dependentes contribuíram com US $\$ 39$ bilhões para a economia dos EUA. A Associação em questão estima que no mesmo período foram criados 455.622 empregos. No ano acadêmico de 20152016, a presença de estudantes internacionais em universidades estadunidenses foi responsável por 32,8 bilhões de dólares e pela geração de 400.812 empregos - para cada sete estudantes internacionais matriculados, três empregos foram criados e mantidos com o consumo de serviços tais como alojamento, alimentação, transporte, telecomunicação, saúde, seguro e lazer (NAFSA, 2018).

A educação superior internacional no Reino Unido - que, em termos de recrutamento de estudantes internacionais perde apenas para os Estados Unidos - também pode ser associada a uma indústria. De acordo com Walker (2014), a renda total do setor da educação superior alcança 22,2 bilhões de libras, dos quais dois bilhões são provenientes da presença de estudantes internacionais. A estimativa é que no conjunto contribua com 800 milhões de libras para o Produto Interno Bruto do país. Além disso, estima-se que visitas dos familiares dos estudantes são responsáveis por algo em torno de 170 milhões de libras / ano (WALKER, 2014).

Em parte, isso explica porque em 2011 os Estados Unidos se tornaram o país piloto do PCsF (MILHOMEM, 2016), responsável por acolher aproximadamente o triplo de bolsistas (27.821), quando comparado ao $2^{\circ}$ colocado, o Reino Unido (10.740). A forte presença de universidades de países anglo-falantes justifica a preocupação com a fluência do inglês por parte dos bolsistas, a criação do Programa Idiomas sem Fronteiras (IsF) e a parceria estabelecida com o Educational Teaching Service (ETS) na aplicação de testes cujos resultados revelem o nível de proficiência dos candidatos a bolsistas, na língua inglesa. Uma das evidências desse padrão é o fato de que em 2013, o envio de estudantes para Portugal foi cancelado sob o argumento de que "a língua inglesa é uma das prioridades do programa, 
por isso o MEC pretende aumentar as relações com instituições de ensino dos EUA"7.

A agressividade do investimento em MAI contribuiu para o Brasil avançar no ranking de países que mais enviam estudantes para as universidades estadunidenses. De acordo com os dados da Open Doors (IIE, 2016), de $14^{\circ}$ lugar, em 2011, o País passou para $6^{\circ}$ lugar, em 2015. Em contrapartida, no mesmo período (2011-2015), houve discreta presença de estudantes estadunidenses nas universidades brasileiras, em grande parte proporcionada pelo Programa 100.00 Strong in the Americas. Contudo, de acordo com o secretário-assistente de diplomacia pública do Escritório de Negócios Ocidentais, do governo estadunidense, Jefferson Brown (G1 Educação, 2014), tem crescido o número de estudantes estadunidenses fazendo algum tipo de formação superior no Brasil. Para se ter ideia do tamanho da assimetria existente entre a capacidade de atração dos dois países (EUA/Brasil), no ano letivo 2011-2012, apenas 4.060 estadunidenses desembarcaram no Brasil para estudar, o que representou $16,5 \%$ a mais que no ano anterior, 3.485 (MORENO, 2014).

No Reino Unido (Escócia, Inglaterra, Irlanda do Norte e País de Gales), por sua vez, há universidades que datam do século XII. Desde o Império que a internacionalização do Ensino Superior é encarada como assunto estratégico uma vez que é associada ao interesse de avançar nas conquistas territoriais e preservar o domínio do reino britânico (WALKER, 2014). O governo britânico reconhece o Ensino Superior como uma indústria de exportação (WALKER, 2014). Consoante a essa visão, de acordo com o relatório sobre a saúde financeira do Ensino Superior britânico, assinado pelo Higher Education Funding Council for England (HEFCE), enquanto o crescimento da receita oriunda de anuidades de estudantes não-europeus foi estimado em $£ 3.7$ bilhões entre 2015-2016, entre 20182019 há expectativas de ela atingir $£ 4.8$ bilhões. Isso corresponde a $14.9 \%$ do total da receita atual (HEFCE, 2016). Compreensivelmente o Reino Unido sinalizou interesse de receber bolsistas do PCsF, assim sendo, entre

7 http://g1.globo.com/educacao/noticia/2013/04/portugal-sera-excluido-do-ciencia-sem-fronteiras-diz-mercadante.html. 
$2012^{8}$ e 2015 foram enviados 11.352 estudantes para as universidades britânicas, destes, um pouco mais de $80 \%$ cursavam a graduação.

No escopo da estratégia de se manter atrativo entre as alternativas dos estudantes interessados em experiências de MAI, o governo britânico classifica o Brasil como um dos parceiros internacionais. Por essa razão, em 2015, o Foreign Commonwealth Office (FCO), órgão governamental britânico, incluiu em sua agenda de trabalho a área educacional (Education and Knowledge) nas campanhas do Prosperity Fund. A principal estratégia adotada pelo Prosperity Fund em relação à pasta da Educação Superior residiu em identificar as universidades britânicas com potencial de participar do PCsF (BRITISH-EMBASSY-BRASILIA, 2015). Coerente com o propósito de manter o UK como um dos principais destinos dos estudantes brasileiros, em 2014, o Ministro das Finanças (George Osborne) declarou que até 2019 a região investiria $£ 45$ milhões em programas de cooperação com o Brasil, provenientes do Fund Newton (BRITISH-COUNCIL, 2014) e no início de 2016 foi firmado um acordo entre Brasil e UK para agilizar o reconhecimento mútuo de diplomas expedidos (MEC, 2016).

Otimista com os ganhos proporcionados pelo PCsF, o governo britânico fortaleceu a parceria entre o Programa Idioma sem Fronteiras (2012) e o Prosperity Fund, passando a financiar cursos de capacitação de professores de inglês. Desse modo, além de contribuir para a formação professores, promove uma espécie de aculturação britânica junto a esses formadores de opinião. Contudo, frente à decisão de o Governo brasileiro interromper o PCsF, o governo britânico decidiu alterar suas prioridades e o Ensino Médio Técnico ganha particular atenção. Nessa trilha, a Embaixada Britânica e a Pearson firmam parceria com o Centro Paula Souza (CPS) para implementar programas de capacitação de professores de língua inglesa nas Escolas Técnicas (Etecs) e Faculdades de Tecnologia (Fatecs) estaduais brasileiras (CPS, 2016). Assim, favorecem a criação de laços institucionais que influem na escolha pelo Reino Unido na etapa posterior à formação técnica. Esse tipo de acordo firmado é classificado

8 Com exceção dos EUA, editais do PCsF para demais países começaram a ser divulgados a partir de 2012. 
com soft service, "requer uma proximidade física entre fornecedor e cliente" (RIVAS; MULLET, 2016, p. 14).

Diferentemente dos Estados Unidos, a MAI ocorre unilateralmente, uma vez que não constam dados oficiais acerca da presença de estudantes britânicos nas universidades brasileiras. A reduzidíssima participação é justificada com distintos argumentos, enquanto alguns autores apontam para limitações financeiras e baixo capital linguístico dos estudantes (FINDLAY et al., 2010), outros enfatizam a superioridade das universidades britânicas, quando comparadas às congêneres de outros países, associada à decisão de não validação de créditos concluídos fora do Reino Unido (BALLATORE; BLOSS, 2007).

Determinado a promover a internacionalização das universidades e obter resultados de curto e médio prazo, o governo brasileiro fortalece o PCsF (AVEIRO, 2014; MULLER, 2013) e o montante de recurso implicado desperta o interesse de governos e universidades internacionais. Nesse contexto, crescem as iniciativas voltadas para a compreensão do sistema de ensino superior, particularmente das universidades brasileiras, que possam favorecer a formalização de parcerias voltadas para a promoção do ensino de idiomas nas universidades públicas, o financiamento de estudos sobre o sistema de educação superior, o financiamento de publicações e guias capazes de auxiliar as universidades no "necessário" processo de internacionalização, entre outras, como se observa na Tabela 5.

\section{PCSF e o direcionamento institucional da internacionalização das uni- versidades brasileiras}

O PCsF foi associado à concessão de bolsas de estudo predominantemente direcionadas para graduandos, assim sendo, atingiu sobretudo a comunidade acadêmica formada por iniciantes, com limitada capacidade de no curto e médio prazo reverter as conquistas acadêmicas para a Instituição de origem do bolsista. Contudo, a sua presença, em grande número, em mais de 50 países e em sólidas universidades, colocou o Ensino Superior brasileiro em evidência, despertou o interesse de governos, agências, universidades, programas, grupos de pesquisa e pesquisadores internacionais. Por outro 


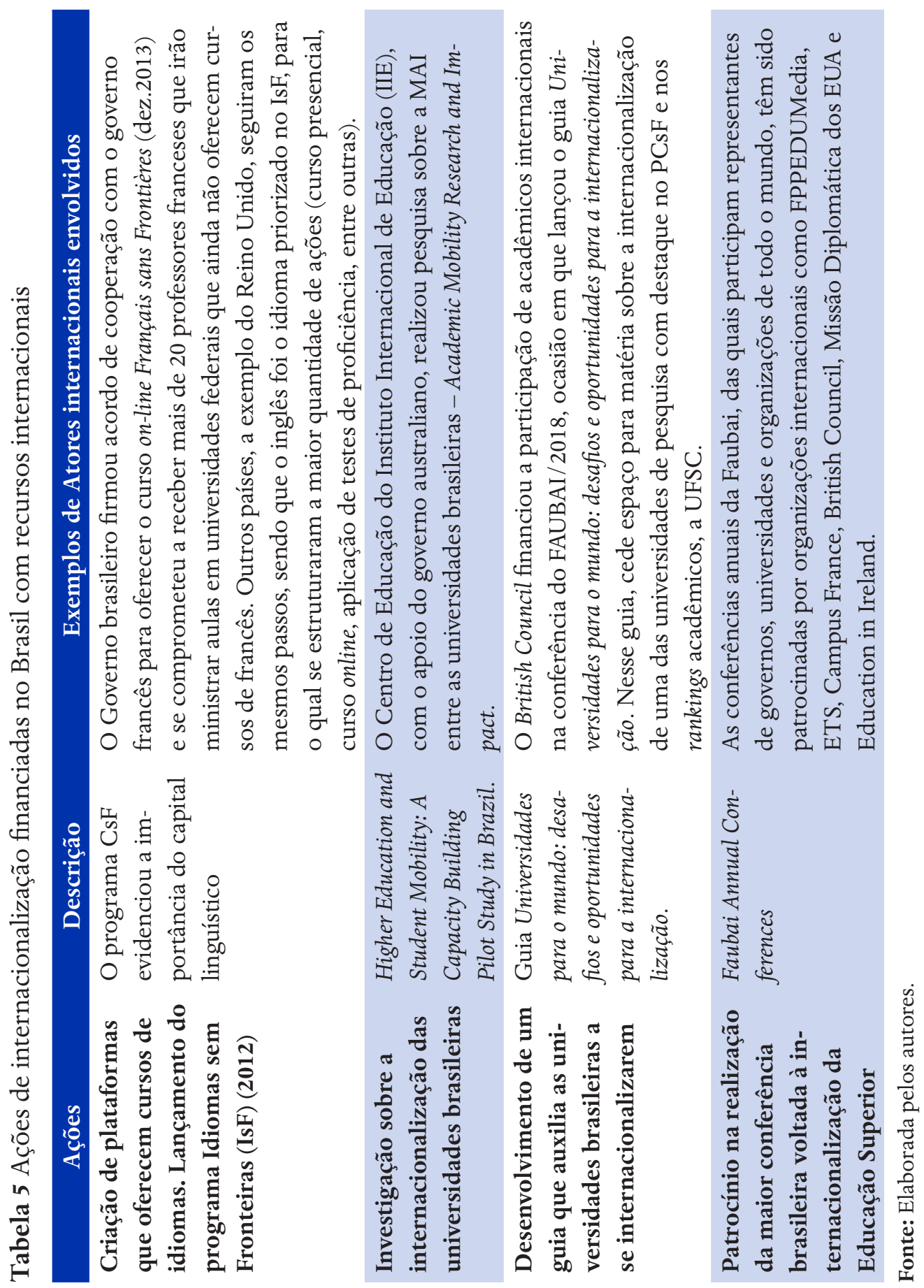


lado, apesar de ter existido por pouco tempo, o programa gerou uma curva de aprendizagem e a determinação de avançar em um processo de internacionalização mais amplo e orgânico com a criação de um ambiente internacional no interior das universidades brasileiras, na direção do que Hudzik (2011) nomeia de internacionalização abrangente (comprehensive internationalization).

Nessa trilha, em 2017, a Capes investiu na realização de um levantamento de dados cujos resultados fundamentaram a elaboração de um diagnóstico acerca do estágio de internacionalização que as universidades brasileiras se encontravam, e a formulação do Programa Institucional de Internacionalização (CAPES-PRINT, 2017) - documento que explicita o modelo de internacionalização atualmente pensado para o país.

O Capes-PrInt ultrapassa os limites de um programa que pulveriza os investimentos públicos com a concessão de bolsas de estudo para graduandos. Ao contrário, concentra os recursos financeiros no apoio a projetos assinados por acadêmicos vinculados a universidades com exposição ao ambiente internacional e reconhecida musculatura acadêmica - de acordo com o Edital n ${ }^{\circ} .41 / 2017$, no momento da submissão, a instituição propositora deve ter "ao menos quatro Programas de Pós-Graduação (PPG) recomendados pela Capes na avaliação trienal de 2013 e na quadrienal de 2017, entre os quais deverá haver, pelo menos, dois com cursos de doutorado" (CAPES-PRINT, 2017, p. 1).

Além disso, o Edital nutre expectativas de atrair projetos de internacionalização orgânicos porque transversalmente alinhados ao Plano de Desenvolvimento Institucional (PDI) da universidade, induzindo as lideranças acadêmicas a revisarem o PDI de modo a direcionar a Instituição para o ambiente internacional. Afinal, uma das justificativas do Capes-PrInt reside em "fomentar a transformação das instituições participantes em um ambiente internacional” (CAPES-PRINT, 2017, p. 2). Assim sendo, para além da competência acadêmica, espera-se que os acadêmicos tenham familiaridade com o PDI, do contrário não conseguirão elaborar uma proposta de internacionalização alinhada à missão que justifica a existência da Instituição. 
A decisão de o governo federal apoiar prioritariamente as universidades com reconhecida produção acadêmica e consistente exposição ao ambiente internacional é reforçada por Thiengo (2018). Ao examinar o PDI ${ }^{9}$ de universidades brasileiras que têm em comum o fato de constarem nos rankings acadêmicos globais (ARWU e THE), estarem classificadas entre as dez primeiras no Ranking Universitário Folha (RUF) e no Projeto Top 200, e oferecerem programas de pós-graduação inseridos no Programa Universidade em Rede do BRICS, a autora classifica as instituições em nove universidades públicas (USP, UFGRS, UFMG, Unifesp, UFABC, Unicamp, UnB e UFSC) que orientam as respectivas missões, metas e estratégias para um processo de transformação em Universidade de Classe Mundial (UCM) (THIENGO, 2018, p. 291-292). Ambição que está em fina sintonia com o modelo de internacionalização expresso pelo PrInt.

De algum modo, a expectativa de êxito dos projetos aprovados pode ser associada ao fato de o Edital respeitar as escolhas da universidade propositora, e dessa forma incentivar o avanço da ciência e da tecnologia em campos de conhecimento que a Instituição revela consistente e reconhecido percurso acadêmico. Isso justifica a ênfase nos consolidados programas de pós-graduação, familiarizados com a concepção de projetos realizados em redes de colaboração que envolvem estudantes e pesquisadores, nacionais e internacionais - um grupo exposto aos indicadores de avaliação adotados internacionalmente. Assim sendo, o Governo brasileiro não dissimula a expectativa de no curto prazo o País se apropriar do conhecimento gerado pelos bolsistas do referido programa. Nos termos do Edital n ${ }^{\circ}$. 41/2017, pretende-se

fomentar a construção, a implementação e a consolidação de planos estratégicos de internacionalização das instituições contempladas nas áreas do conhecimento por elas priorizadas; estimular a formação de redes de pesquisas internacionais com vistas a aprimorar a qualidade da produção

9 O PDI é um planejamento elaborado por cada IES para sistematizar as competências, objetivos, ações estratégicas e metas para a realização de projetos de expansão e qualificação institucional voltadas para o ensino, pesquisa e extensão. Geralmente, o PDI tem cinco anos de duração, está em consonância com a vocação da instituição e as características da região de atuação (THIENGO, 2018). 
acadêmica vinculadas à pós-graduação; ampliar as ações de apoio à internacionalização na pós-graduação das instituições contempladas (CAPES-PRINT, 2017, p. 1)

Cento e oito instituições de Educação Superior e institutos de pesquisa se inscreveram no Edital ( $\left.\mathrm{n}^{\circ} .41 / 2017\right)$, o resultado inicial (ago. / 2018) aprovou 25 projetos, quando retificado (out./2018), mais 11 foram selecionados. A realização dos 36 projetos envolverá um investimento correspondente a R\$ 300 milhões anuais, a partir de 2019 (BUARQUE, 2015; CAPES; CNPQ, 2016) - valor incomparável ao direcionado para o PCsF (10,5 bilhões de reais). Frente às limitações orçamentárias, o PrInt atinge reduzido número de projetos (36), associados a poucas universidades, predominantemente públicas, fortemente orientadas para pesquisa. Curiosamente, o mesmo grupo que, de acordo com Thiengo (2018), direciona as respectivas missões, metas e estratégias para as transformações requeridas pelo padrão de UCM.

A racionalidade do investimento é compreensível e os efeitos colaterais são previsíveis: haverá reforço da lógica dual uma vez que o PrInt irá colaborar para o alargamento da distância que separa universidades de ensino e de pesquisa (em mais esta oportunidade a pesquisa irá se sobrepor à atividade de ensino-aprendizagem), universidades orientadas para o local e para o global, universidades para poucos e universidades para a massa. 


\section{CONSIDERAÇÕES FINAIS}

Levando em conta que o desenvolvimento de competências globais ganha destaque quando se deseja trabalhar em comunidades científicas globais e internacionalizadas (RIVAS; MULLET, 2016), investir em políticas e programas que fomentem a internacionalização da Educação Superior não tem sido uma questão de escolha, o desafio reside em saber como promover isso. Nessa trilha, seria impossível desconsiderar que no contexto brasileiro o PCsF assumiu importância na medida em que ajudou a projetar a Educação Superior e a universidade brasileira no ambiente internacional. O texto apresentado reúne vários indícios disso, dentre os quais sublinha-se particularmente a realização de reuniões internacionais, em variados formatos (fóruns, workshops, palestras, visitas técnicas etc.), cujos participantes buscavam explicar ou compreender a Educação Superior brasileira em geral e o PCsF em particular, além da posição das jovens universidades brasileiras nos rankings regionais e globais em período posterior ao lançamento do PCsF (2011).

A presença de delegações internacionais no Brasil e a promoção de visitas técnicas de gestores acadêmicos às universidades internacionais sinalizavam que o Brasil despertava interesse entre os representantes dos países com reconhecida tradição universitária. Muito mais expostas ao ambiente internacional, algumas universidades brasileiras orientam os recursos disponíveis para uma agenda de internacionalização que ultrapassa a MAI de graduandos na medida em que desejam integrar redes de pesquisa/publicação; ocupar espaços institucionais dedicados à discussão e deliberação acerca de temas internacionais; dispor de profissionais capazes de trabalhar com uma agenda de internacionalização e a defesa dos interesses institucionais fora do Brasil, avançando no diálogo com os pares internacionais (CAPES, 2017).

Os avanços observados revelam a tendência de, em consonância com as exigências da economia do conhecimento, a internacionalização da Educação Superior seja concebida segundo uma perspectiva "abrangente” (HUDZIK, 2011), não mais limitada a uma de suas dimensões - 
como a MAI ou a internacionalização do currículo -, mas desafiada pelas transformações estruturais requeridas; não mais centrada nos indivíduos, mas nas instituições que apresentarem maior capacidade de formular e realizar projetos em rede e isso favoreça uma inserção "ativa" no contexto internacional (LIMA; CONTEL, 2011), reagindo às pressões exercidas pelo governo brasileiro.

Os indícios de que um contingente específico de universidades públicas caminha rumo à consolidação de seu processo institucional de internacionalização denota continuidade histórica em termos de política de Estado, uma vez que, como reflexo da forte presença estatal na Educação Superior do País, o processo de internacionalização do setor se iniciou de maneira induzida a partir de prioridades desenvolvimentistas, com maior projeção nas universidades públicas (LIMA; CONTEL, 2009). Por outro lado, tais indícios reforçam o caráter circunstancial da internacionalização, cujos rumos são influenciados pelos atores internos da instituição (SEEBER et al., 2016).

A decisão de interromper o PCsF, anunciada em junho de 2016 e concretizada em abril de 2017 (CAPES, 2016; MENINO, 2017), gerou um vazio. Contudo, a publicação do Edital ( $n^{\circ}$. 41/2017) que inaugura o Capes-PrInt teve como uma de suas bases o aprendizado gerado pelo PCsF (CAPES, 2017). O documento sinaliza que as universidades brasileiras terão autonomia para definir os parceiros nacionais e internacionais com quem nutrem o interesse de desenvolver projetos de internacionalização. Para isso, desde a partida, precisam dispor de uma infraestrutura de internacionalização que expresse clara capacidade de utilizar idiomas estrangeiros, hospedar estudantes e pesquisadores forâneos, apropriar-se do conhecimento conquistado pelos bolsistas repatriados, dispor de um escritório de relações internacionais com capacidade de promover a gestão dos projetos de internacionalização e capacitar a equipe técnica.

Os resultados da investigação conduzida por Thiengo (2018), que analisou o PDI de 14 universidades brasileiras, associados aos resultados do levantamento de dados conduzido pela Capes (2017) reforçam que uma das principias contribuições do PCsF reside em influir para que a interna- 
cionalização entre no cerne do planejamento estratégico das universidades brasileiras. Esse direcionamento institucional sinaliza que as universidades do País estão se credenciando para promover uma internacionalização mais ampla, ativa e orgânica, que ultrapassa a MAI e constrói um ambiente internacional no cotidiano da instituição, com a pretensão de equilibrar um processo de internacionalização "ativo" e "passivo" (LIMA; CONTEL, 2011). As inúmeras críticas direcionadas ao PCsF são contundentes por serem fundamentadas, mas conforme evidenciado nesse estudo, o desafio consiste em (re)conhecer e preservar os resultados alcançados com a implantação do referido programa. 


\section{REFERÊNCIAS}

AKKARI, A. Internacionalização das Políticas Educacionais: transformações e desafios. Petrópolis: Vozes, 2011.

ALMEIDA, S. M. C. Do Maranhão para o mundo e vice-versa: Ciência sem Fronteiras como política de internacionalização do IFMA. 2016. 184 f., Dissertação (Mestrado em Educação) - Programa de Pós-Graduação em Educação, Universidade Federal do Maranhão, São Luís, 2016.

ALTBACH, P. G.; HAZELKORN, E. Can we measure education quality in global rankings? University World News, 25 ago 20182018.

ARAYA, M. J. M.; OREGIONI, M. S. Internacionalización de la Universidad en el marco de la Integración Regional. Tandil: Grafi kart, 2015.

ARCHANJO, R. Moving globally to transform locally? Academic mobility and language policy in Brazil. Lang Policy, p. 1-22, 2016.

AVEIRO, T. M. M. O programa Ciência sem Fronteiras como ferramenta de acesso à mobilidade internacional. Tear: Revista de Educação, Ciência e Tecnologia, v. 3, n. 2, p. 1-21, 2014.

AZEVEDO, M. L. N. D. The Bologna Process and higher education in Mercosur: regionalization or Europeanization? International Journal of Lifelong Education, v. 33, n. 3, p. 411-427, 2014.

BALLATORE, M.; BLOSS, T. Le sens caché de la mobilité des étudiants Erasmus. In: DERVIN, F. e SUOMELA-SALMI, E. (Ed.). Mobilité académique - perspectives croisées. Turku: Université de Turku/Département d’Études Françaises, 2007. p. 30-63.

BASTOS, A. O. Gestão do Programa Ciência sem Fronteiras nos cursos de graduação da área de Saúde em universidades brasileiras. 2017. 130 f. Dissertação (Mestrado em Educação) - Mestrado Profissional em Educação, Faculdade Pernambucana de Saúde, Recife, 2017.

BERRY, C.; TAYLOR, J. Internationalisation in higher education in Latin America: policies and practice in Colombia and Mexico. Higher Education, v. 67, n. 5, p. 585-601, 2014.

BIDO, M. C. F. Ciência com fronteiras: a mobilidade acadêmica e seus impactos. 2015. $132 \mathrm{f}$. Dissertação (Mestrado em Gestão Educacional) - Programa de Pós-Graduação em Gestão Educacional, Universidade do Vale do Rio dos Sinos, São Leopoldo, 2015.

BISCHOFF, V. As ações públicas de internacionalização da educação superior no Brasil e seu alinhamento com a Política Externa Brasileira no Governo Dilma Rousseff 2011-2014. 2017. 245 f. Tese (Doutorado em Estudos Estratégicos Internacionais) - Programa de Pós-Graduação em Estudos Estratégicos Internacionais, Universidade Federal do Rio Grande do Sul, Porto Alegre, 2017. 
BORGES, R. A.; GARCIA-FILICE, R. C. A língua inglesa no Ciência sem Fronteiras: paradoxos na política de internacionalização. Interfaces Brasil/Canadá, v. 16, n. 1, p. 72 $101,2016$.

BRASIL. Decreto $n^{\circ}$ 7.642, de 13 de Dezembro de 2011. Institui o Programa Ciência sem Fronteiras. 2011. Disponível em: <www.planalto.gov.br/ccivil_03/_Ato2011-2014/2011/Decreto/D7642.htm>. Acesso em: 20 set. 2016.

BRITISH-COUNCIL. Fund Newton. 2014. Disponível em: <www.britishcouncil.org.br/ atividades/educacao/newton-fund?_sm_au_=iHV9qnRL0rHHs6Sn\&_ga $=1.113538759$. 1538528310.1481048566 >. Acesso em: 22 set. 2016.

BRITISH-EMBASSY-BRASILIA. Prosperity Fund Strategy Brazil Programme FY 2015/16. 2015. Disponível em: <www.gov.uk/government/uploads/system/uploads/attachment_data/file/378048/PUBLIC_Brazil_Prosperity_Fund_Programme_Strategy_ FY2015-16.pdf>. Acesso em: 15 dez. 2016.

BUARQUE, C. Relatório de avaliação de políticas públicas: Programa Ciência sem Fronteiras. 2015. Disponível em: < www19.senado.gov.br/sdleg-getter/public/getDocument?docverid $=$ d96d0b6a-8fd9-4526-bbd9-32a9e4d71d48 > . Acesso em: 22 set. 2016.

CAPES-PRINT. Programa Institucional de Internacionalização - Capes-PrInt EDITAL $n^{\circ}$. 41/2017 2017. Disponível em: <www.capes.gov.br/images/stories/download/editais/ 10112017-Edital-41-2017-Internacionalizacao-PrInt-2.pdf>. Acesso em: 20 out. 2018.

CAPES. Esclarecimento sobre regulamento de bolsas no exterior. 2016. Disponível em: $<$ http: / / capes.gov.br/ sala-de-imprensa/noticias/ 7962-esclarecimento-sobre-regulamento-de-bolsas-no-exterior>. Acesso em: 20 mar. 2017.

CAPES. A internacionalização na Universidade Brasileira: resultados do questionário aplicado pela CAPES. Brasília, 2017. Disponível em: <www.capes.gov.br/images/stories/ download/diversos/A-internacionalizacao-nas-IES-brasileiras.pdf $>$. Acesso em: 20 out. 2018.

CAPES; CNPQ. Painel de Controle do Programa Ciência sem Fronteiras - dados atualizados até Janeiro/2016. 2016. Disponível em: <www.cienciasemfronteiras.gov.br/web/csf/painel-de-controle>. Acesso em: 22 set. 2016.

CASTRO, C. D. M. et al. Cem mil bolsistas no exterior. Interesse nacional, v. 5, n. 17, p. 25-36, 2012.

CHAVES, G. M. N. As bolsas de graduação-sanduiche do programa ciência sem fronteiras: uma análise de suas implicações educacionais. 2015. 196 f. Dissertação (Mestrado em Educação) - Programa de Pós-Graduação em Educação, Universidade Católica de Brasília, Brasília, 2015.

CHAVES, V. L. J.; CASTRO, A. M. D. A. D. Internacionalização da educação superior no Brasil: programas de indução à mobilidade estudantil. Revista Internacional de Educação Superior, v. 2, n. 1, p. 118-137, 2016. 
COSTA, N. C. Internacionalização da Educação Superior e o Programa Ciência Sem Fronteiras: um estudo na Universidade Federal Fluminense. 2016. 145 f. Dissertação (Mestrado em Políticas Públicas e Formação Humana) - Programa em Políticas Públicas e Formação Humana, Universidade do Estado do Rio de Janeiro, Rio de Janeiro, 2016.

CPS. Parceria do CPS com Embaixada Britânica capacitará professores de inglês. 2016. Disponível em: <www.cps.sp.gov.br/noticias/2016/outubro/10a_parceria-do-cps-com-embaixada-britanica-capacitara-professores-de-ingles.asp >. Acesso em: 20 out. 2018.

DE WIT, H. Rationales for Internationalisation of Higer Education. Millennium: Journal of International Studies, v. 11, n. july, p. 1-8, 1998.

DE WIT, H. et al. The globalization of internationalization: emerging voices and perspectives. New York: Routledge, 2017.

DOBBINS, M. Convergent or divergent Europeanization? An analysis of higher education governance reforms in France and Italy. International Review of Administrative Sciences, v. 83, n. 1, p. 177-199, 2015.

DOLBY, N.; RAHMAN, A. Research in international education. Review of Educational Research, v. 78, n. 3, p. 676-726, 2008.

EGRON-POLAK, E.; HUDSON, R. IAU 4th Global Survey - Internationalization of higher education: growing expectations, fundamental values. IAU, 2014.

EWERT, S. Higher education cooperation and networks in the Baltic Sea Region: A basis for regionalization and region building? Journal of Baltic Studies, v. 43, n. 1, p. 95-116, 2012.

FINDLAY, A. M. et al. Motivations and experiences of UK students studying abroad. Research Paper no. 8, p. 1-74, 2010.

FRANÇA, T.; PADILLA, B. Cooperação Sul-Sul, uma via alternativa? Um caso exploratório entre Brasil e Argentina. Forum Sociológico. Série II, 2015. CESNOVA. p.61-71.

FRANCO, M. L. P. B. Análise de conteúdo. Brasilia: Líber Livro, 2007.

GACEL-ÁVILA, J. Comprehensive internationalisation in Latin America. Higher Education Policy, v. 25, n. 4, p. 493-510, 2012.

GACEL-ÁVILA, J.; RODRÍGUEZ-RODRÍGUEZ, S. Internacionalización de la educación superior en América Latina y el Caribe: Un Balance. Universidad de Guadalajara; Benemérita Universidad Autónoma de Puebla: Unesco-Iesalc, 2018.

GAO, Y. Toward a set of internationally applicable indicators for measuring university internationalization performance. Journal of studies in international education, v. 19, n. 2, p. 182-200, 2015.

GIGLIO, R. Impacto do programa ciências sem fronteiras nas competências de seus egressos. 2015. 63 f. Dissertação (Mestrado em Engenharia de Produção) - Programa de Pós-Graduação em Engenharia de Produção, Universidade Federal Fluminense, Niterói, 2015. 
HAZELKORN, E. Rankings and the reshaping of higher education: The battle for world-class excellence. London: Palgrave Macmillan, 2011.

HEFCE. Financial health of the higher education sector 2015-16 to 2018-19 forecasts. 2016. Disponível em: < www.hefce.ac.uk/media/HEFCE,2014/Content/Pubs/2016/201634/ HEFCE2016_34.pdf >. Acesso em: 20 mar. 2017.

HUDZIK, J. K. Comprehensive internationalization: From concept to action. Washington, DC: NAFSA, 2011.

IIE. Open Doors. 2016. Disponível em: <www.iie.org > Acesso em: 20 out. 2018.

JÖNS, H.; HOYLER, M. Global geographies of higher education: The perspective of world university rankings. Geoforum, v. 46, p. 45-59, 2013.

JUDD, K. E. 101 mil brasileiros no mundo: as implicações do Programa Ciência Sem Fronteiras para o Estado Desenvolvimentista Brasileiro. 2014. 138 f. Dissertação (Mestrado em Ciências Sociais) - Programa de Pós-Graduação em Estudos Sobre as Américas Universidade de Brasília, Brasília, 2014.

KEHM, B. M.; TEICHLER, U. Research on internationalisation in higher education. Journal of Studies in International Education, v. 11, n. 3-4, p. 260-273, 2007.

KNIGHT, J. Internationalization remodeled: Definition, approaches, and rationales. Journal of studies in international education, v. 8, n. 1, p. 5-31, 2004.

KNIGHT, J. Concepts, rationales, and interpretive frameworks in the internationalization of higher education. In: DEARDOFF, D. K. E. A. (Ed.). The SAGE handbook of international higher education. London: SAGE Publications Inc, 2012. p. 27-42.

KNIGHT, J. International universities: Misunderstandings and emerging models? Journal of Studies in International Education, v. 19, n. 2, p. 107-121, 2015.

KNOBEL, M. Brazil seeks academic boost by sending students abroad. International Higher Education, v. 66, p. 15-17, 2012.

LAGE, T. S. R. Politicas de internacionalização da Educação Superior na Região Norte do Brasil: Análise do Programa Ciência sem Fronteiras na Universidade Federal do Tocantins. 2015. 182 f. Dissertação (Mestrado em Desenvolvimento Regional) - Programa de Pós-Graduação em Desenvolvimento Regional, Universidade Federal do Tocantins, Palmas, 2015.

LEAL, F. G.; MORAES, M. C. B. Decolonialidade como epistemologia para o campo teórico da internacionalização da educação superior. Education Policy Analysis Archives, v. 26, n. 87 , p. 1-29, 2018.

LEAL, F. G.; STALLIVIERI, L.; MORAES, M. C. B. Indicadores de internacionalização: o que os Rankings Acadêmicos medem? Revista Internacional de Educação Superior, v. 4, n. 1, p. 52-73, 2017.

LEITE, D. B. C.; GENRO, M. E. H. Avaliação e internacionalização da educação superior: Quo vadis América Latina? Avaliação: Revista da Avaliação da Educação Superior, v. 17, n. 3, p. 763-785, 2012. 
LIMA, M. C.; CONTEL, F. B. Períodos e motivações da internacionalização da educação superior brasileira. Sème coloqque del l'IFBAE, 2009.

LIMA, M. C.; CONTEL, F. B. Internacionalização da educação superior: nações ativas, nações passivas e a geopolítica do conhecimento. São Paulo: Alameda, 2011.

MACHADO-DA-SILVA, C. L.; FONSECA, V. S. D. Competitividade organizacional: uma tentativa de reconstrução analítica. Organizações \& Sociedade, v. 4, n. 7, p. 97-114, 1996.

MARGINSON, S.; ORDORIKA, I. 'El central volumen de la fuerza'. Global hegemony in higher education and research. In: RHOTEN, D.; CALHOUN, C. (Ed.). Knowledge matters: The public mission of the research university. New York: Columbia University Press, 2011. p. 67-129.

MARINGE, F.; FOSKETT, N.; WOODFIELD, S. Emerging internationalisation models in an uneven global terrain: Findings from a global survey. Compare: a journal of comparative and international education, v. 43, n. 1, p. 9-36, 2013.

MEC. Acordo inédito entre Brasil e Reino Unido vai agilizar reconhecimento mútuo de diplomas. 2016. Disponível em: <http:/ / portal.mec.gov.br/ultimas-noticias/212-educacao-superior-1690610854/35441-acordo-inedito-entre-brasil-e-reino-unido-vai-agilizar-reconhecimento-mutuo-de-diplomas>. Acesso em: 20 mar. 2017.

MENINO, F. O fim do Ciência sem Fronteiras. Carta Capital, 26 abr. 2017, 2017.

MILHOMEM, R. B. B. Implementação do Programa Ciência Sem Fronteiras no Estado do Tocantins: limites, desafios e potencialidades. 2016. 143 f. Dissertação (Mestrado em Gestão de Políticas Públicas) - Programa de Pós-Graduação em Gestão de Políticas Públicas, Universidade Federal do Tocantins, Palmas, 2016.

MORAES, R. Análise de conteúdo. Revista Educação, 1999.

MORENO, A. C. EUA lançam plano para aumentar o $n^{\circ}$ de americanos estudando no Brasil. 2014. Disponível em: <http://g1.globo.com/educacao/noticia/2014/09/ eua-lancam-plano-para-aumentar-o-n-de-americanos-estudando-no-brasil.html> . Acesso em: 15 out. 2016.

MORLEY, L. et al. Internationalisation and migrant academics: the hidden narratives of mobility. Higher Education, v. 76, n. 3, p. 537-554, 2018.

MOROSINI, M. C.; DALLA, M. C.; GUILHERME, A. Internationalization of Higher Education: A Perspective from the Great South. Creative Education, v. 8, n. 01, p. 95-113, 2017.

MOROSINI, M. C.; NASCIMENTO, L. M. D. Internacionalização da Educação Superior no Brasil: a produção recente em teses e dissertações. Educação em Revista, v. 1, n. 33, p. 1-27, 2017.

MULLER, C. Ensino superior no Brasil: a caminho de Ciência sem Fronteiras? In: DANE, F. (Ed.). Relações Brasil-Alemanha. Rio de Janeiro: Cadernos Adenauer XIV, edição especial, Konrad Stiftung, 2013. p. 43-53. 
NAFSA. Find out how your state and district benefit from international students. 2018. Disponível em: <www.nafsa.org > . Acesso em: 20 out. 2018.

NORTH, D. C. Institutions, Institutional Change and Economic Performance. Cambridge: University Press, 1990.

OECD. Education at a Glance 2016: OECD Indicators. 2016. Disponível em:

$<$ http:/ / dx.doi.org/10.1787/ eag-2016-en>. Acesso em: 28 jan. 2018.

OECD. Education at a Glance 2017: OECD Indicators. 2017. Disponível em:

$<$ http:/ / dx.doi.org/10.1787/ eag-2017-en>. Acesso em: 28 jan. 2018.

PRASAD, P. Crafting qualitative research: working in the postpositivist traditions. New York: ME Sharpe, 2005.

QS. University Rankings - Top Universities. 2017. Disponível em: <www.topuniversities. com>. Acesso em: 15 dez. 2017.

RAMOS, A. G. Programa Ciência sem Fronteiras: desdobramentos e análise das possíveis contribuições à formação acadêmica dos bolsistas. 2016. 85 f. Dissertação (Mestrado em Educação) - Programa de Pós-Graduação em Educação, Pontifícia Universidade Católica de São Paulo, São Paulo, 2016.

RIBEIRO, C. P. D. S. Análise do Programa Ciência sem Fronterias (CsF) e de sua Efetividade na Promoção da Visibilidade Internacional dos Trabalhos Científicos dos Programas de Pós-graduação do Centro de Ciências Exatas e Tecnolóficas / UFV. 2014. 112 f. Dissertação (Mestrado em Administração Pública em Rede Nacional) - Programa de Pós-Graduação em Administração Pública em Rede Nacional, Universidade Federal de Viçosa, Viçosa, 2014.

RIVAS, R. M.; MULLET, S. Countervailing institutional forces that shape internationalization of science: an analysis of Brazil's Science without Borders program. RAI Revista de Administração e Inovação, v. 13, n. 1, p. 12-21, 2016.

RODRIGUES, S. B.; CARRIERI, A. D. P. A tradição anglo-saxônica nos estudos organizacionais brasileiros. RAC, v. 5, n. Edição Especial, p. 81-102, 2001.

RUBIÃO, A. História da Universidade: genealogia para um modelo participativo. Coimbra: Ed. Almedina, 2013.

SÁNCHEZ, E. D.; MUÑOZ, M. D. C.; BENÍTEZ, E. F. V. La Gestión de Internacionalización de la Educación Superior en las Universidades Públicas de Paraguay. In: ARAYA, J. M. J. (Ed.). Aportes para los estudios sobre Internacionalización de la Educación Superior en América del Sur. Tandil: Universidad Nacional del Centro de la Provincia de Buenos Aires, 2015. p. 137-162.

SANTOS, B. D. S. A universidade do século XXI: para uma reforma democrática e emancipatória da Universidade. 3.ed. São Paulo: Cortez, 2011.

SCOTT, W. R. Institutions and organizations: foundations for organizational science. London: Thousand Oaks, 1995. 
SCOTT, W. R. Approaching adulthood: the maturing of institutional theory. Theory and society, v. 37, n. 5, p. 427-442, 2008.

SEEBER, M. et al. Why do higher education institutions internationalize? An investigation of the multilevel determinants of internationalization rationales. Higher education, v. 72, n. 5, p. 685-702, 2016.

SEHNEM, P. R. Relações entre os contributos de Programas de Mobilidade Internacional e a Competência Comunicativa Intercultural de Estudantes Universitários. 2015. 356 f. Tese (Doutorado em Educação) - Programa de Pós-Graduação em Educação, Universidade do Vale do Itajaí, Itajaí, 2015.

SHIELDS, R. Reconsidering regionalisation in global higher education: Student mobility spaces of the European Higher Education Area. Compare: A Journal of Comparative and International Education, v. 46, n. 1, p. 5-23, 2014.

STAKE, R. E. A arte da investigação com estudos de caso. 4.ed. Lisboa: Fundação Calouste Gulbenkian, 2016.

STEIN, S. Internationalization for an uncertain future: Tensions, paradoxes, and possibilities. The Review of Higher Education, v. 41, n. 1, p. 3-32, 2017.

TERRIER, E. Mobilités et expériences territoriales des étudiants internationaux en Bretagne: interroger le rapport mobilités spatiales-inégalités sociales à partir des migrations étudiantes. 2009. 474 f. Université Rennes 2; Université Européenne de Bretagne, 2009.

THE. World Uiversity Rankings 2016-2017. 2017. Disponível em: <www.timeshighereducation.com>. Acesso em: 25 ago. 2018.

THIENGO, L. C. Universidade de Classe Mundial e o consenso pela excelência: tendências globais e locais. 2018. 365 f. Tese (Doutorado em Educação) - Programa de Pós-Graduação em Educação, Universidade Federal de Santa Catarina, Florianópolis, 2018.

UFSC. UFSC ocupa a posição de 101-150a no ranking Golden Age University. 2018. Disponível em: <http:/ / sinter.ufsc.br/2018/06/08/ufsc-ocupa-a-posicao-de-101-150-no-rankingtimes-higher-education $>$. Acesso em: 25 ago 2018.

USP. Na $118^{a}$ posição, USP é a brasileira mais bem avaliada no QS Ranking. 2018. Disponível em: <https://jornal.usp.br/institucional/ na-118a-posicao-usp-e-a-brasileira-mais-bem-avaliada-no-qs-ranking $>$. Acesso em: 25 ago 2018.

VELHO, L. Conceitos de ciência e a política científica, tecnológica e de inovação. Sociologias, v. 13, n. 26, p. 128-153, 2011.

VIEIRA, R. C.; LIMA, M. C. Academic Ranking-From Its Genesis to Its International Expansion. Higher Education Studies, v. 5, n. 1, p. 63-72, 2015.

WALKER, P. International student policies in UK higher education from colonialism to the coalition: Developments and consequences. Journal of Studies in International Education, v. 18 , n. 4, p. 325-344, 2014. 
WESTPHAL, A. M. S. Egresso da primeira chamada do programa "Ciência sem Fronteiras": reflexos no sistema educacional brasileiro (Learning with outcomes). 2014. $121 \mathrm{f}$. Dissertação (Mestrado em Educação) - Programa de Pós-Graduação da Universidade Católica de Brasília, Universidade Católica de Brasília, Brasília, 2014.

WHITSED, C.; GREEN, W. What's in a name? A theoretical exploration of the proliferation of labels for international education across the higher education sector. Journal of Studies in International Education, v. 18, n. 2, p. 105-119, 2014.

YEMINI, M.; SAGIE, N. Research on internationalisation in higher education-exploratory analysis. Perspectives: Policy and Practice in Higher Education, v. 20, n. 2-3, p. 90-98, 2015. 


\section{DADOS DOS AUTORES}

\section{IVOR PROLO ivorprolo@unemat.br}

Doutor em Administração pelo PPGA/ESPM

Instituição de vinculação: Universidade do Estado de Mato Grosso (UNEMAT)

Áreas de interesse em pesquisa: Internacionalização da Educação Superior; Integração Regional do Ensino Superior; Mobilidades acadêmica e estudantil; Interculturalidade ORCID: http:/ / orcid.org/0000-0001-6220-7507

Av. Prof. Renato Figueiro Varella Caixa Postal 08 Nova Xavantina/MT 78690-000

\section{ROSILENE CARLA VIEIRA vieira.rosilene@gmail.com}

Doutoranda em Administração pelo PPGA/ESPM

Instituição de vinculação: Escola Superior de Propaganda e Marketing (ESPM)

Áreas de interesse em pesquisa: Internacionalização da Educação Superior; Integração Regional do Ensino Superior; Mobilidades acadêmica e estudantil; Interculturalidade ORCID: https: / / orcid.org/0000-0001-8572-0274

\section{MANOLITA CORREIA LIMA mclima@espm.br}

Doutora em Educação pela USP

Instituição de vinculação: Escola Superior de Propaganda e Marketing (ESPM)

Áreas de interesse em pesquisa: Internacionalização da Educação Superior; Integração Regional do Ensino Superior; Mobilidades acadêmica e estudantil; Interculturalidade ORCID: https: / / orcid.org/0000-0001-6852-2997

\section{FERNANDA GEREMIAS LEAL fernanda.leal@ufsc.br}

Doutoranda em Administração pela UDESC

Instituição de vinculação: Universidade do Estado de Santa Catarina (UDESC) / Boston College (Visiting Scholar)

Áreas de interesse em pesquisa: Educação Superior; Internacionalização da Educação Superior; Estudos Decoloniais e Pós-Coloniais

ORCID: https: / / orcid.org/0000-0002-1716-2060 